Histochem Cell Biol 2008 DOI 10.1007/s00418-008-0447-2

PMID 18512067.

\title{
Hepatitis C virus budding at lipid droplet-associated ER membrane visualized by 3D electron microscopy
}

\author{
Philippe Roingeard ' Christophe Hourioux ' Emmanuelle Blanchard · \\ Gérard Prensier \\ P. Roingeard ${ }^{` C}$. Hourioux $`$ E. Blanchard \\ INSERM ERI 19, Université François Rabelais \& CHRU de Tours, Tours, France \\ e-mail : roingeard@med.univ-tours.fr
}

G. Prensier

UMR CNRS 6023, Université Blaise Pascal, Clermont-Ferrand, France

Corresponding author: Philippe Roingeard, INSERM ERI 19, Laboratoire de Biologie Cellulaire, Faculté de Médecine de Tours, 10 boulevard Tonnellé, F-37032 Tours Cedex France.

Tel (33) 247366071 - Fax (33) 247366090 - E-mail: roingeard@med.univ-tours.fr

\begin{abstract}
The mechanisms underlying hepatitis $\mathrm{C}$ virus (HCV) morphogenesis remain elusive, but lipid droplets have recently been shown to be important organelles for virus production. We investigated the interaction between HCV-like particles and lipid droplets by three-dimensional reconstructions of serial ultrathin electron microscopy sections of cells producing the HCV core protein. The budding of HCV-like particles was mostly initiated at membranes close to the lipid droplets rather than at membranes directly apposed to the lipid droplets. This may have important implications for our understanding of the complex relationship between HCV and lipids and may make easier to dissect out the HCV life cycle.
\end{abstract}

Keywords $\mathrm{HCV}$ ` lipid droplet ` virus morphogenesis ‘ electron microscopy ‘3D 


\section{Introduction}

Recent advances in the cloning of a particular hepatitis C virus (HCV) strain JFH1 (for Japanese fulminant hepatitis clone 1) and in the development of permissive cell culture systems have made it possible, for the first time, to produce infectious HCV that can be efficiently propagated in cultured hepatoma cells (Lindenbach et al. 2005; Wakita et al. 2005; Zhong et al. 2005). Lipid droplets have been shown to be involved in the production of infectious viral particles in Huh7 cells propagating the HCV JFH1 strain. Miyanari et al. (2007) first showed that the HCV core protein recruits the viral replication complex to endoplasmic reticulum (ER) membranes closely surrounding the lipid droplets in infected cells, and that this recruitment is critical for the production of infectious viruses. Also, virusinduced double-stranded RNA foci that probably represent HCV genome replicative intermediates were recently found to be attached to the ER and juxtaposed to the lipid droplets in cells infected with the JFH-1 strain (Targett-Adams et al. 2008). Studies conducted with chimeric genomes have demonstrated that the binding strength of the HCV core protein for lipid droplets is crucial for determining the efficiency of virus assembly (Shavinskaya et al. 2007). However, it remains difficult to precisely identify the site of HCV budding in infected cells. Using immunogold and electron microscopy (EM), Miyanari et al (2007) detected the HCV core protein in the membrane monolayer at the surface of the lipid droplets or in the ER membranes closely surrounding these droplets, but their EM observations did not clearly demonstrate the assembly and presence of virus at this site. We previously reported similar difficulties visualizing and documenting viral particles by EM in cells in which the JFH1 virus is efficiently propagated (Rouillé et al. 2006; Hourioux et al. 2007a). However, viral budding can be mimicked and viewed by EM if the HCV core protein is overproduced with a Semliki forest virus (SFV) replicon vector (Blanchard et al. 2003; Roingeard et al. 2004; Hourioux et al. 2007a). Despite the abortive nature of this HCV-like particle budding, this model remains a useful tool for studies of the early events in HCV assembly. In particular, the use of this model has made it possible to demonstrate that the HCV core protein self-assembles after cleavage by the signal peptide peptidase (SPP) into HCV-like particles at ER membranes, which often appear to be located very close to lipid droplets (AitGoughoulte et al. 2006). However, it is difficult to determine from EM observations of individual ultrathin cell sections whether viral budding occurs at the surface of the lipid droplet or at a membrane separate from the droplet. We thus addressed this question by threedimensional (3D) reconstruction of the cytoplasm of cells overproducing the HCV core protein. Due to the particularly large size of the lipid droplets and/or lipid droplet clusters induced by the HCV core protein, we used a method based on 3D reconstruction of serial EM ultrathin sections to reconstruct cell domains with a thickness up to 1.5 micrometers.

We recently used our SFV model to investigate the molecular basis of HCV genotyperelated steatosis, by comparing the effects of a wild-type 1a HCV core protein with those of a mutant $(\mathrm{Y} 164 \mathrm{~F})$ protein with a genotype 3-specific residue, $\mathrm{F}$ at position 164 (Hourioux et al. 2007b). Lipid droplets accumulated with both constructs, but lipid droplet clusters were more frequent and larger in cells producing the Y164F mutant than in cells producing the wild-type control. Our 3D EM investigation required the prior identification, by light microscopy, of a single cell harboring a cluster of lipid droplets. We therefore studied this particular mutant, known to induce the formation of large clusters of lipid droplets. 


\section{Materials and methods}

BHK-21 cells were cultured and electroporated with recombinant SFV RNA encoding the $\mathrm{HCV}$ core 1a or Y164F protein, as previously described (Hourioux et al, 2007b). As a control, we synthesized a recombinant RNA encoding $\beta$-galactosidase ( $\beta$-gal). Cells were cultured for $16 \mathrm{~h}$ after electroporation, as our previous studies have shown that the major morphological events associated with HCV core protein production occur during this period in this system (Blanchard et al. 2003; Ait-Goughoulte et al. 2006; Hourioux et al. 2007a). Transfected cells were then fixed by incubation for $48 \mathrm{~h}$ in $4 \%$ paraformaldehyde and $1 \%$ glutaraldehyde in 0.1 $\mathrm{M}$ phosphate buffer ( $\mathrm{pH}$ 7.2) and were postfixed by incubation for $1 \mathrm{~h}$ with $1 \%$ osmium tetroxide. They were dehydrated in a graded acetone series, and cell pellets were embedded in Epon resin, which was allowed to polymerize for $24 \mathrm{~h}$ at $60^{\circ} \mathrm{C}$. Ultrathin $(60-70 \mathrm{~nm})$ sections were cut, stained with $1 \%$ uranyl acetate and $1 \%$ lead citrate, placed on EM grids coated with collodion membrane, and observed with a Jeol 1230 electron microscope (Tokyo, Japan) connected to a Gatan digital camera driven by Digital Micrograph software (Gatan, Pleasanton, CA, USA). To quantify the frequency of specific ultrastructural modifications induced by the expression of a given protein, we recorded these changes in 100 consecutive EM sections of cells transfected with each construct. When present, the HCV-like particles were counted in each positive section, to determine their mean number per cell section.

For immunogold labeling, ultrathin sections were treated with $10 \%$ hydrogen peroxide to dissolve the resin polymer. After several washes in PBS, grids were incubated with antiHCV C1856 monoclonal antibody (Virostat, Portland, ME) diluted 1:50 in PBS supplemented with $1 \%$ bovine serum albumin (BSA) for 90 minutes at room temperature. Grids were washed several times in PBS and were then incubated for 90 minutes at room temperature with an anti-mouse antibody conjugated to gold particles $(15 \mathrm{~nm}$ in diameter, British Biocell International, Cardiff, UK) diluted 1:40 in PBS. Sections were washed in PBS, fixed in 4\% glutaraldehyde in PBS and stained as described above with $1 \%$ uranyl acetate and $1 \%$ lead citrate.

After identification of transfected cells with large clusters of lipid droplets on semithin ( $0.5 \mu \mathrm{m}$ thick) sections viewed under light microscope, we resized our Epon blocks precisely around these individual cells, to cut a ribbon of serial ultrathin sections of these cells (60-70 $\mathrm{nm}$ thick). EM grids were stained as described above, and electron micrographs were collected with a digital camera for the same region of cells in each of the series of sections. Images stacks for these serial EM sections were aligned using Photoshop software. Because the electron beam distorts ultrathin sections slightly, it was therefore necessary to align the images based on the position of specific structures of interest. Contours were carefully drawn on the same specific cellular structures from different serial sections, including lipid droplets, ER and viral particles, using IMOD software (http://bio3d.colorado.edu) (Kremer et al. 1996). The contours from a stack of serial sections were then arranged into objects using IMOD. Using the IMODmesh feature of IMOD, we then joined the contours of each object to form a 3D model.

\section{Results and discussion}

EM analysis of BHK-21 cells producing the wild-type (Fig. 1a and 1b) or Y164F mutant (Fig. $1 \mathrm{c}$ and 1d) core protein showed that these proteins self-assembled at the ER membrane. This was demonstrated by the detection of HCV-like particles budding towards the lumen of convoluted ER compartments, consistent with our previous findings (Blanchard et al. 2003; 
Ait-Goughoulte et al. 2006; Hourioux et al. 2007a). We quantified the frequency of specific ultrastructural modifications induced by the production of a given protein, by recording the occurrence of these changes in 100 consecutive EM sections of cells transfected with each construct. Dense convoluted ER membranes similar to those shown in Fig. 1 were detected in $63 \%$ of sections of cells producing the HCV core 1a protein and $55 \%$ of sections of cells producing the Y164F mutant protein. The presence of the HCV core protein in these specific convoluted ER membranes was confirmed by immunogold labeling (Fig. 2a). Moreover, such convoluted ER membranes were never detected in sections of cells transfected with a recombinant SFV vector encoding $\beta$-galactosidase (Fig. 2b). We counted the HCV-LPs present in each positive section, and determined the mean number of these particles per cell section. We observed a mean of $11 \mathrm{HCV}$-like particles on sections of cells producing the $\mathrm{HCV}$ core wild-type 1a protein and 12 on sections of cells producing the Y164F mutant protein. Thus, the wild-type 1a and Y164F mutant core proteins had similar HCV-like particle assembly properties, despite the higher level of lipid droplet formation induced by the Y164F mutant, as reported elsewhere (Hourioux et al. 2007b).

We therefore made use of this Y164F mutant to facilitate the identification of transfected cells with large clusters of lipid droplets on semithin sections viewed under a light microscope. The 3D reconstructions shown in Figs. 3 and 4 demonstrate that HCV-like particles budded from ER membranes closely associated with lipid droplets (see also QuickTime movies of these 3D reconstructions provided as supplemental materials). However, only three of the $81 \mathrm{HCV}$-like particles counted in the 3D space covered by these two reconstructions $(4 \%)$ budded at the surface of lipid droplets. Thus, some budding of HCV-like particles probably occurs at the surface of lipid droplets, but most such particles clearly bud from ER membranes a small distance away from the lipid droplets. Our results conflict, to some extent, with those of Miyanari et al (2007) who suggested that HCV budding is mostly initiated at membranes directly apposed to lipid droplets. It remains unclear whether this discrepancy is due to our experimental system, which produces only the HCV structural proteins and not the HCV non-structural proteins. However, the production of HCV JFH1 in Huh7 hepatoma cells has recently been shown to depend on the assembly and secretion of very low-density lipoproteins (VLDL), which occur in ER membranes (Huang et al, 2007). A confocal microscopy study also showed that an HCV core mutant protein trapped at the transfer site between ER and lipid droplets could not form virions in the JFH1/Huh7 cell model (Boulant et al. 2007). The authors suggested that, as the wild-type core is transferred from the ER membrane to the lipid droplet surface, transfer probably also occurs in the opposite direction, leading to virion assembly in ER membranes (Boulant et al. 2007). Our $3 \mathrm{D}$ reconstructions of the intracellular environment of the lipid droplets in cells producing the HCV core protein support this hypothesis. Nevertheless, the next challenge would be to improve the JFH1 strain propagation model to facilitate visualization of the JFH1 virus by EM, and to use our EM 3D approach based on reconstructions of ultrathin sections to improve our understanding of the morphogenesis of HCV.

Acknowledgements Our work is supported by a grant from ANRS (Agence Nationale de la Recherche sur le SIDA et les hépatites virales) and the Région Centre (Equipe ESPRI). We thank Brigitte Arbeille for her help in setting up our EM studies and Sylvie Trassard for technical assistance with immuno-EM. Our data were obtained with the assistance of the RIOIbisa Electron Microscopy Facility of François Rabelais University.

Supplementary Data QuickTime movies of the 3D reconstructions shown on figures 3 and 4 are provided as supplemental materials. 


\section{References}

Ait-Goughoulte M, Hourioux C, Patient R, Trassard S, Brand D, Roingeard P (2006) Core protein cleavage by signal peptide peptidase is required for hepatitis $\mathrm{C}$ virus-like particle assembly. J Gen Virol 87:855-860

Blanchard E, Hourioux C, Brand D, Ait-Goughoulte M, Moreau A, Trassard S, Sizaret PY, Dubois F, Roingeard P (2003) Hepatitis C virus-like particle budding: role of the core protein and importance of its Asp111. J Virol 77:10131-10138

Boulant S, Targett-Adams P, McLauchlan J (2007) Disrupting the association of hepatitis C virus core protein with lipid droplets correlates with a loss in production of infectious virus. J Gen Virol 88:2204-2213

Hourioux C, Ait-Goughoulte M, Patient R, Fouquenet D, Arcanger-Doudet F, Brand D, Martin A, Roingeard P (2007a) Core protein domains involved in hepatitis C virus-like particle assembly and budding at the endoplasmic reticulum membrane. Cell Microbiol 4:1014-1027

Hourioux C, Patient R, Morin A, Blanchard E, Moreau A, Trassard S, Giraudeau B, Roingeard P (2007b) The genotype 3-specific hepatitis C virus core protein residue phenylalanine 164 increases steatosis in an in vitro cellular model. Gut 56:1302-1308

Huang H, Sun F, Owen DM, Li W, Chen Y, Gale Jr M, Ye J (2007) Hepatitis C virus production by human hepatocytes dependent on assembly and secretion of very lowdensity lipoproteins. Proc Natl Acad Sci USA 104:5848-5453

Kremer JR, Mastronarde DN, McIntosh JR (1996) Computer visualization of threedimensional image data using IMOD. J Struct Biol 116, 71-76

Lindenbach BD, Evans MJ, Syder AJ, Wolk B, Tellinghuisen TL, Liu CC, Maruyama T, Hynes RO, Burton DR, McKeating JA, Rice CM (2005) Complete replication of hepatitis $\mathrm{C}$ virus in cell culture. Science 309:623-626

Miyanari Y, Atsuzawa K, Usuda N, Watashi K, Hishiki T, Zayas M, Bartenshlager R, Wakita T, Hijikata M, Shimotohno K (2007) The lipid droplet is an important organelle for hepatitis C virus production. Nat Cell Biol 9:1089-1097

Roingeard P, Hourioux C, Blanchard E, Brand D, Ait-Goughoulte M (2004) Hepatitis C virus ultrastructure and morphogenesis. Biol Cell 96:103-108

Rouillé Y, Helle F, Delgrange D, Roingeard P, Voisset C, Blanchard E, Belouzard S, McKeating JA, Patel AH, Maertens G, Wakita T, Wychowski C, Dubuisson J (2006) Subcellular localization of hepatitis $\mathrm{C}$ virus structural proteins in a cell culture system that efficiently replicates the virus. J Virol 80:2832-2841

Shavinskaya A, Boulant S, Penin F, McLauchlan J, Bartenschlager R (2007) The lipid droplet binding domain of hepatitis $\mathrm{C}$ virus core protein is a major determinant for efficient virus assembly. J Biol Chem. 282:37158-37169

Targett-Adams P, Boulant S, McLauchlan, J (2008) Visualization of double-stranded RNA in cells supporting hepatitis C virus RNA replication. J Virol 82:2182-2195

Wakita T, Pietschmann T, Kato T, Date T, Miyamoto M, Zhao Z, Murthy K, Habermann A, Krausslich HG, Mizokami M, Bartenschlager R, Liang TJ (2005) Production of infectious hepatitis $\mathrm{C}$ virus in tissue culture from a cloned viral genome. Nat Med 11:791-796

Zhong J, Gastaminza P, Cheng G, Kapadia S, Kato T, Burton DR, Wieland SF, Uprichard S L, Wakita T, Chisari FV (2005) Robust hepatitis C virus infection in vitro. Proc Natl Acad Sci USA 102:9294-9299 

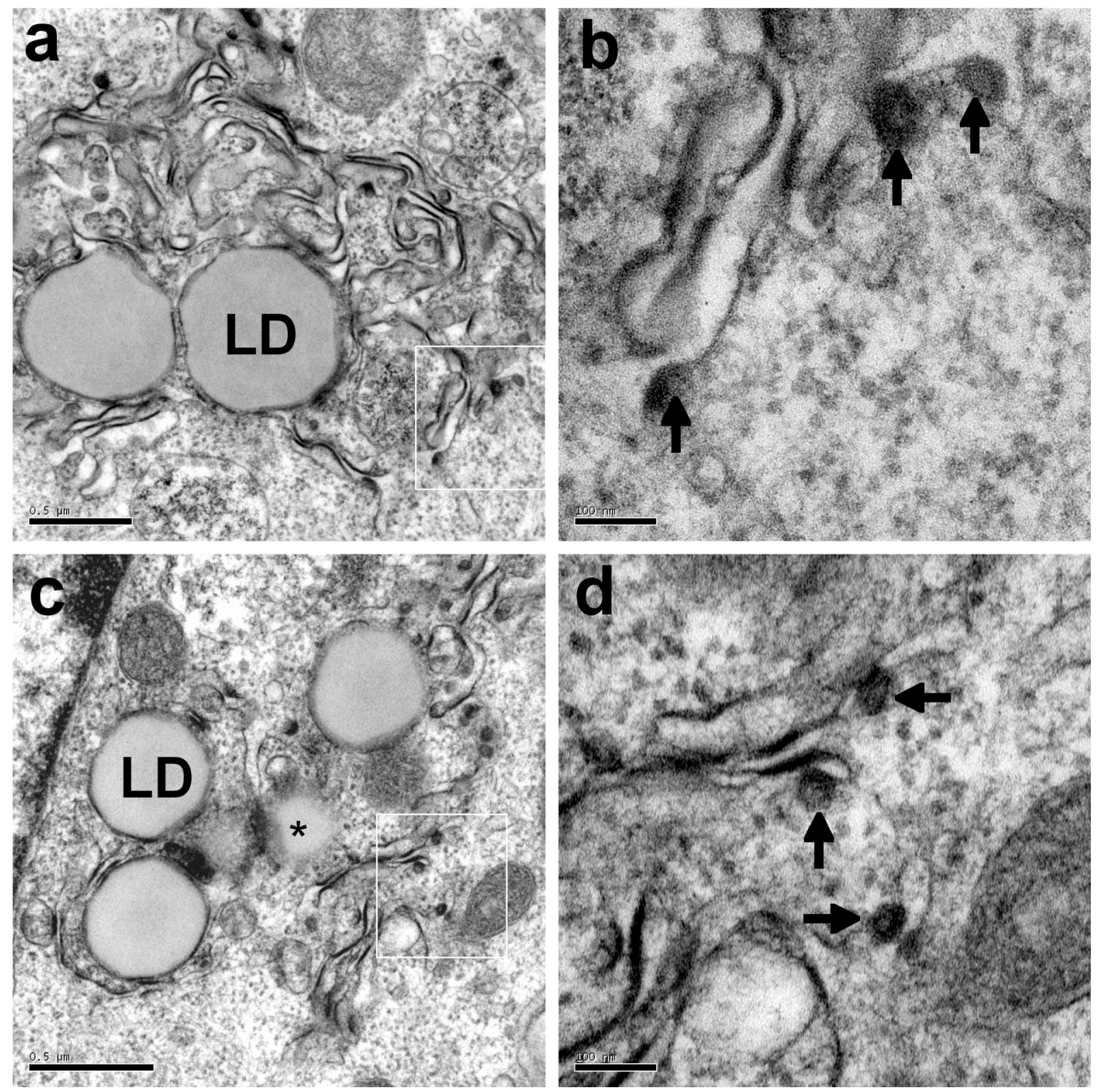

Fig. 1. Electron micrographs of BHK-21 cells producing the HCV core $1 \mathrm{a}(\mathrm{a}, \mathrm{b})$ and $1 \mathrm{aY} 164 \mathrm{~F}$ (c, d) proteins. As shown at low magnification, the production of these proteins led to the presence in the perinuclear area of dense convoluted ER membranes surrounding clusters of lipid droplets (LD, * see also a lipid droplet in tangential section). At higher magnification (panels $\mathrm{b}$ and $\mathrm{c}$ correspond to the white squares in panels a and $\mathrm{c}$, respectively), the budding of HCV-like particles (arrows) was clearly observed to occur at these convoluted ER membranes. Bars $0.5 \mu \mathrm{m}$ (a and c), $100 \mathrm{~nm}$ (b and d). 

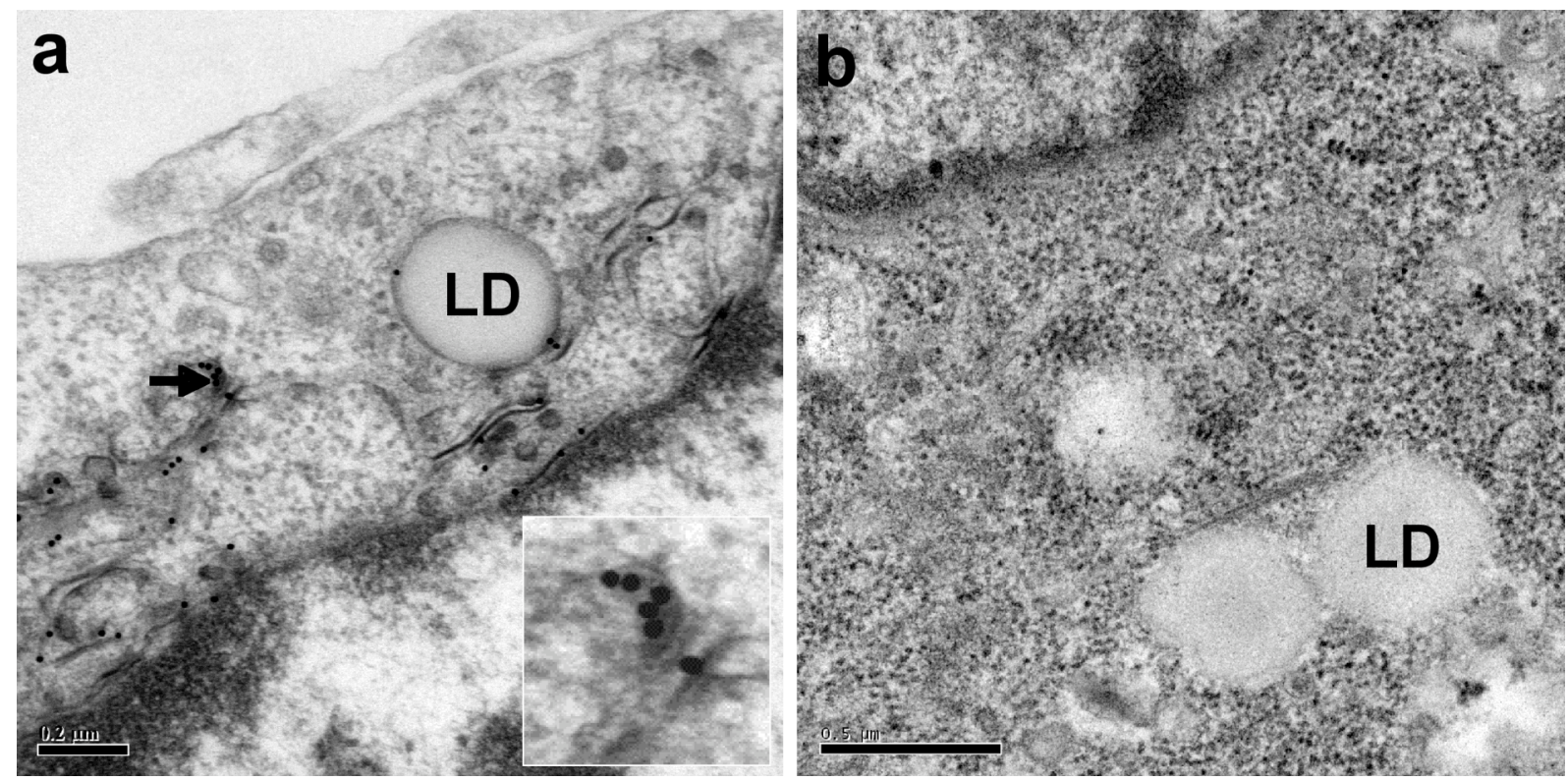

Fig. 2. Electron micrographs of BHK-21 cells producing the HCV core 1a Y164F (a) or $\beta$ galactosidase (b) proteins. The HCV core protein was shown to be present in the convoluted ER membranes, at the surface of lipid droplets (LD), and in the budding HCV-like particles (arrow and high magnification of this area in the inset), by immunogold electron microscopy with a monoclonal anti-HCV core antibody (a). The specificity of these observations was demonstrated by the absence of any convoluted ER membranes surrounding the lipid droplets, and the absence of immunogold labeling in cells producing the $\beta$-galactosidase protein (b). Bars $0.2 \mu \mathrm{m}(\mathrm{a}), 0.5 \mu \mathrm{m}(\mathrm{b})$. 
$\mathbf{A}$
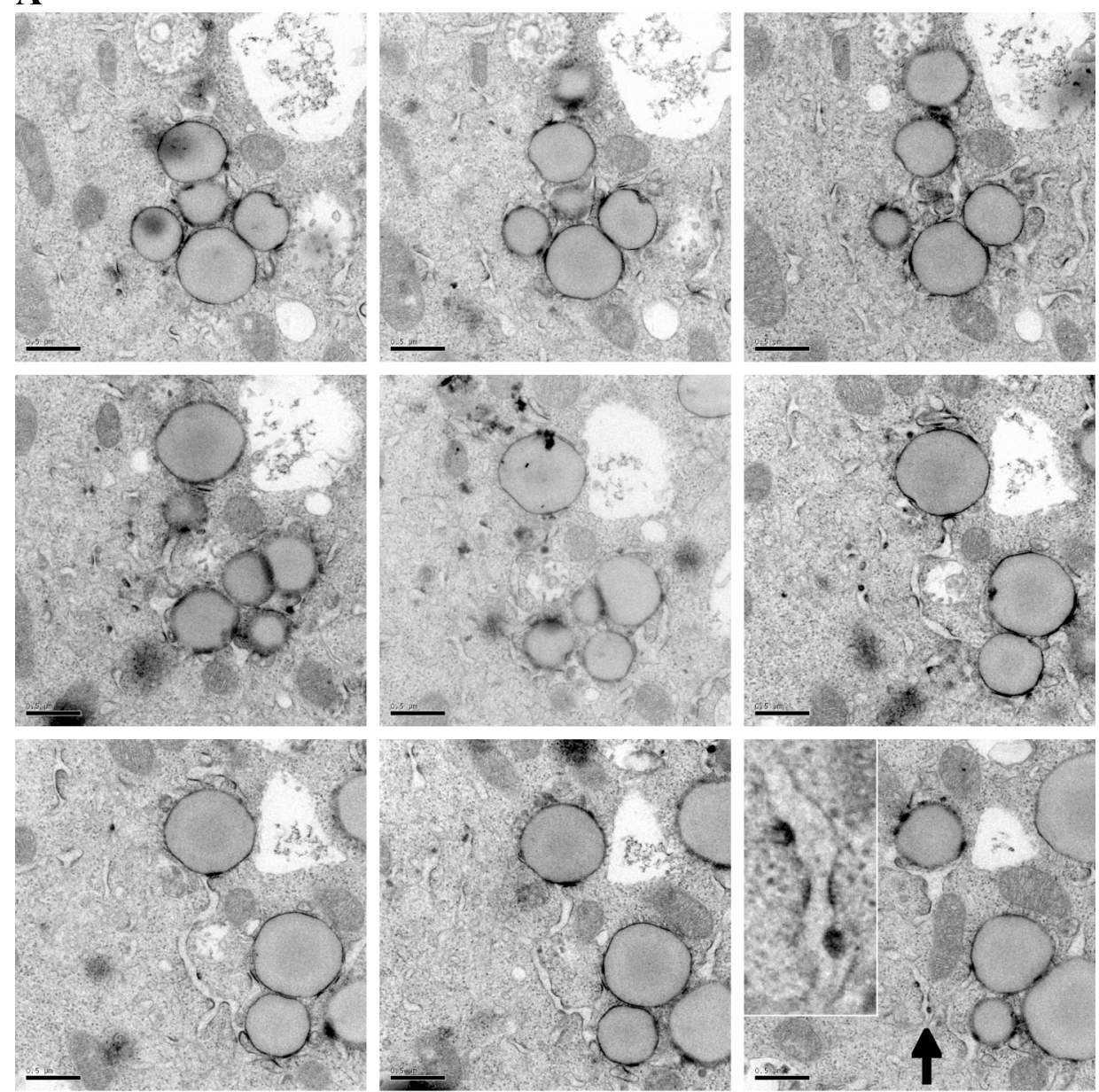

B

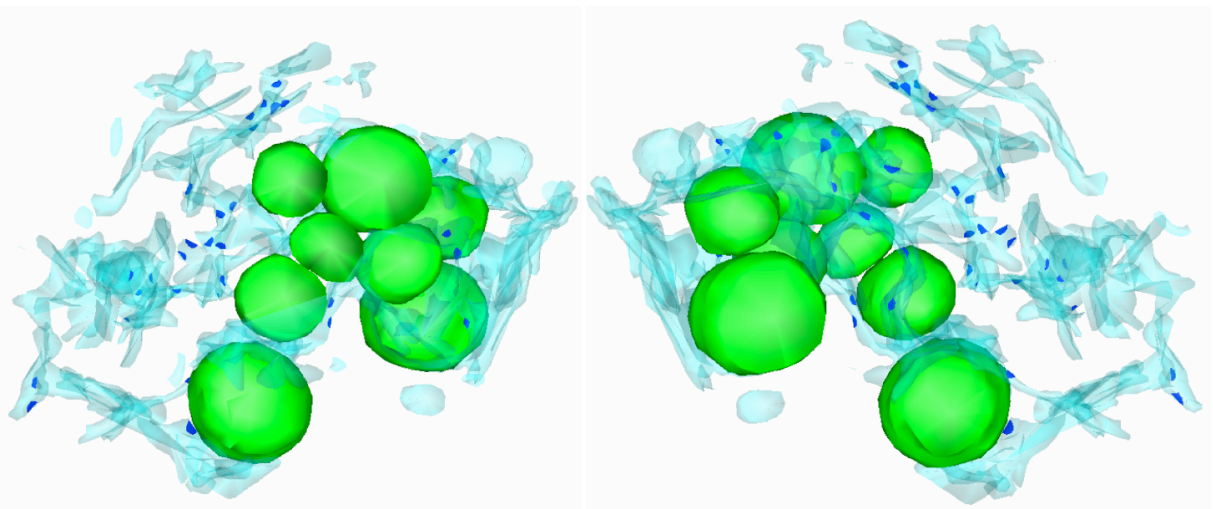

Fig. 3. Three-dimensional reconstruction of a cell producing the HCV core 1a Y164F protein. a : Sample of serial ultrathin (60-70 nm thick) EM sections (the whole stack was made of 15 sections) showing a cluster of lipid droplets and HCV-like particles budding at the convoluted ER membrane surrounding these lipid droplets. These HCV-like particles are more easily observed in larger photographs : see for example an enlarged area for one of these serial sections (arrow indicating a high magnification for this area in the inset). $b$ : Two different views of the area corresponding to these serial sections reconstructed with IMOD software, showing the lipid droplets (green), ER (light blue) and viral particles (dark blue). A QuickTime movie of this 3D reconstruction is also provided as supplemental material (Supplemental file 1). Bars in a, $0.5 \mu \mathrm{m}$. 
$\mathbf{A}$
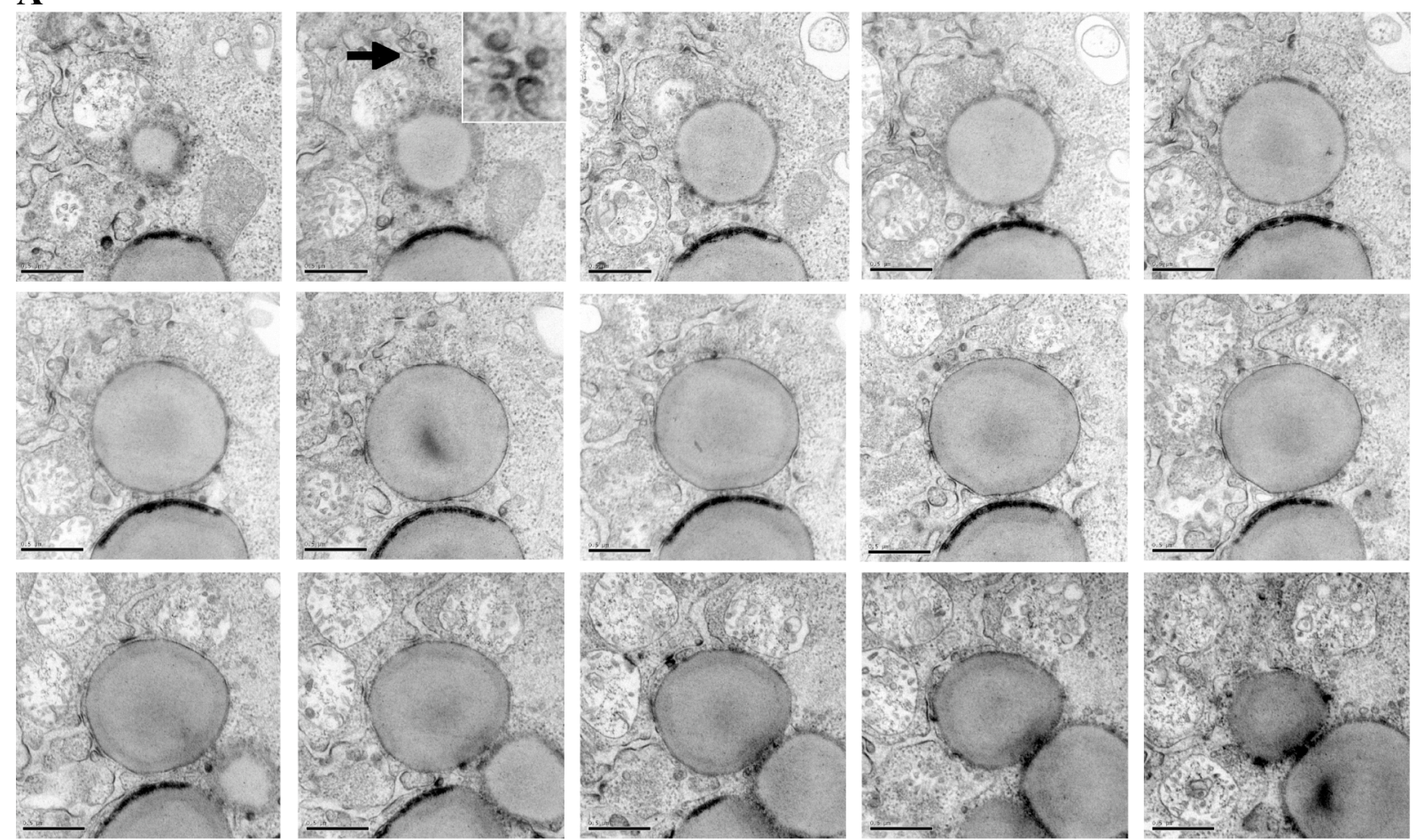

B
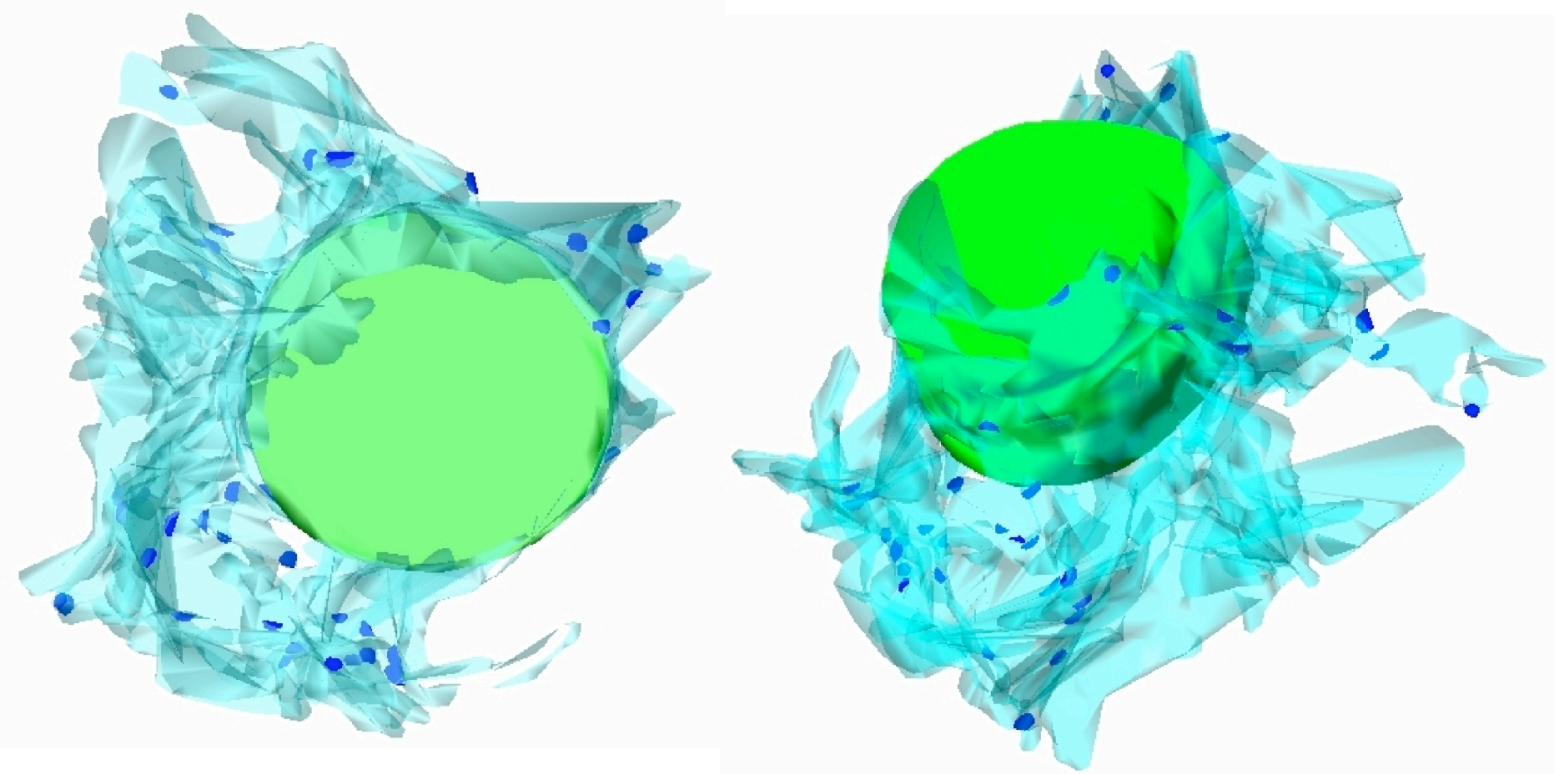

Fig. 4. Three-dimensional reconstruction of a second cell producing the HCV core 1a Y164F protein. a : Sample of serial ultrathin (60-70nm thick) EM sections (the whole stack was made of 19 sections) showing a cluster of lipid droplets and HCV-like particles budding at the convoluted ER membrane surrounding these lipid droplets. These HCV-like particles are more easily observed in larger photographs : see for example an enlarged area for one of these serial sections (arrow indicating a high magnification for this area in the inset). $b$ : Two different views of the area corresponding to these serial sections reconstructed with IMOD software, showing the central large lipid droplet (green), ER (light blue) and viral particles (dark blue). A QuickTime movie of this 3D reconstruction is also provided as supplemental material (Supplemental file 2). Bars in a, $0.5 \mu \mathrm{m}$. 